\title{
Embracing plurality through oral language
}

\section{Bich Nguyen ${ }^{\mathrm{a} 1}$, Rhonda Oliver ${ }^{\mathrm{a}}$, and Judith Rochecouste ${ }^{\mathrm{b}}$}

${ }^{a}$ Curtin University, Perth, Western Australia, ${ }^{b}$ Monash University, Melbourne, Victoria

Bich Nguyen Curtin University, Perth, Western Australia

Bich Nguyen works as a research officer in the School of Education at Curtin University in Western Australia. Her research interests include World Englishes, Systemic Functionalism, Aboriginal education, and language teaching methodology.

bichnhn@hcmup.edu.vn; nhnbich@yahoo.com

Professor Rhonda Oliver Curtin University, Perth, Western Australia

Rhonda Oliver works in the School of Education at Curtin University in Western Australia. Her research areas include language and literacy, particularly child studies of second language acquisition and indigenous education. She has published widely appearing in a number of international and national journals.

rhonda.oliver@curtin.edu.au

Dr Judith Rochecouste Monash University, Melbourne, Victoria Dr Judith Rochecouste is Adjunct Senior Lecturer at the Office of the Pro Vice-Chancellor (Learning and Teaching) at Monash University in Melbourne, Australia. The particular focus in her teaching is student learning, tertiary literacy and diversity. Dr Rochecouste's discipline homes are linguistics and applied linguistics and her research interests include international students' experiences, tertiary student learning, enquiry-based learning, academic/tertiary literacy, Aboriginal education, language variation and creole languages. judith.rochecouste@monash.edu

\footnotetext{
${ }^{1}$ Corresponding author. Email: bichnhn@hcmup.edu.vn; nhnbich@yahoo.com
} 


\title{
Embracing plurality through oral language
}

\begin{abstract}
The transmission and dissemination of knowledge in Aboriginal societies for the most part occurs orally in an Aboriginal language or in Aboriginal English. However, whilst support is given to speaking skills in Indigenous communities, in our education system less emphasis is given to developing equivalent oral communicative competence in Standard Australian English (SAE). Instead the focus is given to the ongoing assessment of reading and writing skills and grammatical knowledge - this is in direct contrast to the existing language experience of Aboriginal students. Therefore, for Aboriginal students to participate in mainstream society, we suggest that there is a need to nurture oral language skills in SAE and provide learners with the experience to develop their code-switching ability to maintain continuity with their first language or dialect. Drawing on previous research that we and others have undertaken at several schools, this paper highlights the need for three fundamental changes to take place within language education: i) School policies to change and explicitly accept and support Aboriginal English in code-switching situations; ii) Familiarity among school staff about the major differences between Aboriginal English and SAE; and iii) Tasks which focus on developing and practising the "when, why and how" of code-switching.
\end{abstract}

Key words: oral language, code-switching, Aboriginal education, plurality, school policy, teacher attitudes

\section{Introduction}

Aboriginal people have an oral tradition that realises their spiritual beliefs and connections to the land and nature (Woods 2010). For thousands of years, Aboriginal 'voices', wisdom and power have been passed from generation to generation by way of oral narrative (Pi-Sunyer 2007; Selby 2013). In their traditional culture, it is through oral narrative that Australian Aboriginal identity is created, established and maintained (Klapproth 2004). Oral language also provides Indigenous Australians with a means to 'create coherence and make narrative sense of their experience' (Klapproth 2004, 5). Added to this, oral language is the traditional Indigenous teaching tool and usually takes the form of storytelling (McKeough et al. 2008) or 'yarning' (Bessarab and Ng'andu 2010).

While spoken language dominates Indigenous people's lives, it is reading and writing skills and grammatical knowledge that are extensively taught and assessed in the Australian educational system. Currently this is realised through the annual testing conducted under the auspices of The National Assessment Program Literacy and Numeracy (NAPLAN). For this reason and because of a number of other contributing factors, a significant gap exists between Aboriginal students' academic achievement and those of other groups, including recently arrived children of migrants. For example, an analysis of NAPLAN test results in 2010 revealed that four out of every ten Aboriginal students failed these tests (Santow 2010). In a report of Indigenous education in 2011, it was found that the NAPLAN failure rate (plus absent) of Aboriginal students in Victoria, South Australia, Western Australia and the Northern Territory was 40\%, 48\%, 53\%, 71\% respectively (Hughes and Hughes 2012). This 
continues to cause grave concerns for educators and policy makers (Wigglesworth, Simpson and Loakes 2011; R. Gardner and Mushin 2013).

Although a number of initiatives have been instigated, these efforts to assist Aboriginal students have been largely unsuccessful. For example, a recent study of the effectiveness of specific, targeted education programs funded by the government (total funds expended being \$359 million in 2008-2009 and \$659 million in 2012-2013, Australian Government 2013) and designed to support Indigenous students' academic performance shows a continuation of the status quo regarding Aboriginal educational achievement (Hughes and Hughes 2012). In 2012, while $92 \%$ of Australian students overall met national minimum standards (Kirk 2012), many primary schools in Queensland attended exclusively by Indigenous students failed to "lift a single student" (Chilcott 2012a, 5) above the standard in the 2012 NAPLAN. As a further illustration, although the Aurukun campus of the Cape York Aboriginal Australian Academy in Queensland has received multimillion-dollar investments, none of its Indigenous students scored close to the national average in writing, grammar, punctuation and numeracy in 2012 (Chilcott 2012b). In fact, Indigenous students in such rural and remote areas have slipped even further behind their non-Indigenous peers, scoring 'the worst-ever result in Year 9 numeracy' in the 2013 NAPLAN tests (Chilcott 2013, 7). Therefore, despite the funding and resources aimed at improving Aboriginal outcomes, the gap in performance continues.

Clearly other factors must be contributing to these results and what these might be has been the subject of much debate. Low student socio-economic background and little teacher accountability have been suggested as possible contributing factors (Warren and deVries 2009). Intelligence, particularly differences between the types valued in Western educational contexts and traditional Aboriginal society have also been suggested, although most acknowledge as does Stevenson $(2012,6)$ that 'Indigenous kids are just as clever as nonIndigenous kids.' Many Aboriginal students have also been diagnosed as having hearing, language and speech development problems (Ball 2009; Peltier 2010). A concerning consequence of this is their removal from mainstream classrooms and placement in special education units, as if they had learning disabilities (Smail 2012). Absenteeism, often for cultural and familial reasons, is also acknowledged as contributing to lack of achievement amongst the Aboriginal student population and language and cultural differences have been consistently identified as core issues (McGregor 2011; Pond 2012; Hughes and Hughes 2012). Although a number of initiatives have been implemented, there is no doubt that teachers continue to struggle with what they see as their Aboriginal students' cultural and linguistic difference, which, in turn, has a negative impact on student outcomes.

It is not just teachers who struggle to reconcile and work in positive ways with regard to language and cultural differences. As Wigglesworth et al. (2011) point out, the fact that plurality is not embraced in the design of NAPLAN may be a cause of Aboriginal students' continued low levels of performance on such assessments. Indeed, NAPLAN is normreferenced and designed for, and targeted at, standard Australian English speakers, whereas many Indigenous students grow up in communities where the primary means of communication is their traditional languages, English-based Creoles (Kriol) and/or Aboriginal English (Standing Council on School Education and Early Childhood 2013; 
Wigglesworth et al. 2011). This draws into question the appropriacy of using such an assessment tool for this cohort, but also, and perhaps more importantly, the efficacy of the current pedagogy used with Aboriginal students.

Despite their lack of appropriacy, NAPLAN and other assessment tools are the primary ways academic success is judged. At the same time, academic success is crucial to Indigenous students as it affords them better employment opportunities (Warren and deVries 2009). As the current Australian Prime Minister, Tony Abbott, rightly maintains in a recent report to the parliament about Indigenous education and unemployment, 'it's hard to find work without a basic education and it's hard to live well without a job' (as cited in Griffiths 2014, para. 9). However, the sad news is that Indigenous employment has continued to "slip backwards" in recent years due to declining education results (Griffiths 2014, para. 6). Therefore, while several measures have been put in place, (e.g., increasing funding to schools, policies to encourage Aboriginal and Torres Strait students to attend school, and stressing the responsibilities of communities and parents, Kirk 2012), we maintain it is of paramount importance to develop teaching and assessment methods that will assist Aboriginal students to close the gap in terms of achievement.

\section{Oral language development through code-switching}

It has been long recognised that the development of oral language plays a fundamental role in the cultivation of students' meta-cognitive abilities (Warren and deVries 2009; Moschkovich 2005). It is a 'social thinking tool' (Setati and Alder 2001, 246) as students need to talk to learn (Martin, 1999; Ball, 2009). Not surprisingly, oral language improvement has been reported to correlate with improved literacy attainment (Ball 2009; Peterson 2012) and constitutes an important component of the multiliteracies pedagogical approach that includes multiple discourses realised in various text forms (oral, written and digital) (Lavoie, Sarkar, Mark and Jenniss 2012). Spoken language development is even more important for Indigenous students whose home language is vastly different from school discourse (Warren and deVries 2009). Although most Aboriginal students speak some kind of English, their variety of English, despite it being systematic and highly rule-bound, differs substantially from SAE in terms of both formal features and semantic content (Sharifian 2000; Eades 2013). Indeed, 'even where Aboriginal English seems to employ the same vocabulary as Australian English, it is informed by a semantics deeply rooted in Aboriginal culture' (Malcolm and Rochecouste 2000, 98). Therefore, to help them bridge their first dialect/language and SAE, we maintain that Indigenous students' spoken language should be promoted through the encouragement of code-switching. Later, we illustrate this drawing on a case study of previous school-based research.

The cognitive benefits of code-switching, 'a well governed process used as a communicative strategy to convey linguistic and social information' (Grosjean 1999, 286), have been welldocumented. Brain researchers have found that those who code-switch use more brain area than those who do not (George and George 2010). In addition, recent research on frontal lobe 
functioning in bilingual students has revealed that code-switching helps accelerate complex cognitive processing (Byrd 2012). Students who code-switch have reportedly outperformed their monolingual peers on non-linguistic tasks that require cognitive control (Blackburn 2013). Blackburn (2013) claims that this is because speakers who code-switch develop an inhibitory control ability through the process of switching between languages, alternating between inhibition and activation as they switch back and forth, a cognitive capacity that is not cultivated in monolingual students. Thus those who code-switch possess a higher level of executive control, a type of superior cognitive function (Byrd 2012; Ljungberg et al. 2013) and, therefore, have a better ability for controlling their attention and retrieving information when performing non-verbal tasks (Byrd 2012; Ljungberg et al. 2013). They have also been found to possess better verbal episodic memory than monolinguals due to the activation of the prefrontal cortex (Ljungberg et al. 2013).

Empirical studies on the effects of code-switching on students' classroom engagement have further consolidated the benefits of this 'learning and teaching resource' (Setati and Alder 2001, 246). Code-switching has been encouraged by some content teachers as it facilitates students' understanding (Uys and Van Dulm 2011; Mokgwathi and Webb 2013). For example, teachers in Botswana and Malaysia have been observed to use idiomatic expressions from their students' home languages to improve their comprehension (Mokgwathi and Webb 2013; Then and Ting 2011). Moreover, this 'dynamic communicative strategy' (Kieswetter 1995, 6) has been found to enhance class participation and discussion (Mokgwathi and Webb 2013; Uys and Van Dulm 2011), promoting opportunities for 'exploratory talk' and thus facilitating the meaning-making within the learning process (Setati \& Alder 2001, 246). In addition, code-switching helps students to expand their vocabulary by learning equivalent words (Mokgwathi and Webb 2013; Tian and Macaro 2012). For Indigenous students elsewhere in the world, such as in Zimbabwe, code-switching has been found to foster understanding of Western educational concepts, enabling them to link Western social and natural scientific notions to Indigenous ways of understanding, knowing and perceiving (Shizha 2007). Code-switching also allows classroom order to be maintained and disruptive behaviour controlled (Uys and Van Dulm 2011).

It should be acknowledged, however, that fluid code-switching cannot be acquired overnight, but is a cognitively demanding skill that takes time and practice (Peltier 2010; Zevenbergen, Grootenboer and Sullivan 2010; Public Health Advocacy Institute WA 2013). Lo Bianco (2008) points out that bilinguals who code-switch go through various stages of developing competence in both codes, from experiences of self-doubt and low self-efficacy to mastering both codes and code-switching comfortably between them. Moreover, students who can code-switch proficiently demonstrate more efficient cognitive processing in their preferred code, however, if their preferred code is eliminated, they may perform below their ability (Moschkovich 2005).

Given these potential benefits, it is not surprising that code-switching has been encouraged in bi-dialectal curricula in some countries and states, for example, in Canada (Lo Bianco 2008; Peltier 2010), Botswana (Mokgwathi and Webb 2013), Western Australia (Welch, Konigsberg, Rochecouste and Collard in press), New South Wales (Standing Council on 
School Education and Early Childhood 2013), and the Northern Territory in Australia (Wigglesworth et al. 2011) to facilitate Aboriginal students' acquisition of standard English. In Canada, it has been recommended that teaching programs be developed 'to support [Indigenous students'] code-switching between "school talk" and "home talk" rather than provision of direct clinical interventions for speech and language' (Peltier 2008, 568). In Australia, advocacy of Aboriginal students' code-switching has been reported to bring several educational benefits: improved self-esteem, attention, desire to learn, sense of belonging in school and decreased attrition (Department of Education and Department of Training and Workforce Development WA 2012, Focus Area 1, 83).

In certain parts of Australia, however, schools have been less embracing of Aboriginal students' language backgrounds and, instead use approaches that can be uncomfortable and alienating for the students, and rather than promoting their Aboriginality, the use of their home language is discouraged in the classroom (Forrest 2013). To overcome this, we argue that the development of their oral language through the explicit use of code-switching can play a valuable role in facilitating the transition from home to school and improving school performance. Specifically, we maintain that code-switching enables educational institutions to embrace plurality through oral language, and as we show in our case study, Aboriginal community members are strongly supportive of such a position.

\section{Code-switching and Aboriginality}

Language is not only a means of communication, but it is the realisation of culture as well as enabling the expression of thinking and being (Shizha 2007; New South Wales Department of Education and Training 2008). The challenge that educators face is how to incorporate the values and beliefs that Aboriginal students bring from home into the school curriculum (Department of Education and Training 2005, 67). The promotion of code-switching between school dialect and home dialect is, therefore, a pedagogical approach that enables school knowledge to be brought closer to the Indigenous student's home life. Code-switching, moreover, provides Aboriginal students with a secure sense of identity for they are able to express who they are with ease (Hornberger and Swinehart 2012). The acceptance and encouragement of Aboriginal code-switching also reduces the threat posed to Aboriginal English users who might have already identified English as their first language (Department of Education and Department of Training and Workforce Development WA 2012, Focus Area 12, 165). As Wishart $(2009,470)$ contends, 'development and validation of individual identities is a crucial component of self-esteem and success in schools.'

Research has shown that the prohibition of Aboriginal home languages in the classroom has led to negative emotional and academic results. George and George $(2010,2)$ describe their feeling of shame when they, as young Canadian Aboriginal students, were made to believe that the variety of English they had been using since childhood was only 'broken English.' Atleo and Fitznor $(2010,14)$ describe the cases of two Canadian Aboriginal students who had to suppress their Aboriginality and the linguistic competence that they had achieved in the 
early years of their lives in order to learn the language of school where 'English! Only English is spoken.' They reported feeling displaced, frightened and alienated from their culture, their land and even themselves when they were not allowed to breathe a word of their heritage. Shizha (2007) reported a similar situation in some parts of Zimbabwe where 'cognitive apartheid' (Cobern 1996) still dominates and Indigenous students' voices are 'silenced' and their identities suppressed. The result has been low learning motivation and high levels of attrition. Moreover, Feldman, Stone and Renderer (1990) found that high school students in a Hawaiian Creole-speaking community underperformed because selfexpression in their home language was not permitted. While an Aboriginal student can be confident with their communication skills in their home community, they "may become bewildered and reluctant to engage in learning if [their] language is not given equal value" to Standard English (Department of Education and Training 2005, 67). It is now acknowledged that the discouragement of Aboriginal students' home language leads to a common attitude that 'the school is not respecting my home language, which is part of me and my identity, so school is not about me' (Sharifian 2008, 132). From the above studies, it is evident that the encouragement of code-switching is fundamental to help Indigenous students develop their standard English in a way that is culturally relevant to them and aligns with their 'Aboriginal epistemology' (McKeough et al. 2008, 148). Therefore, 'the impetus for change' (Peltier 2010, 131) in education should recognise the important role of Aboriginal students' home language (namely Aboriginal English, Kriol or other languages) in the construction of their coherent identity within the school context.

\section{Our case study}

This case study has been drawn from research conducted over a number of years in a Vocational Education and Training (VET) context at a registered training organisation located on the outskirts of a Western Australia regional centre. In Australia, VET has been recognised by the government as holding a critical role in the creation of a skilled workforce to enhance the productivity of the economy (Zoellner 2012). Within this context, Aboriginal students have tended to select hands-on VET school courses as a pathway to success rather than academic post-secondary studies (Schwab 2001; Richardson 2013). In recent years, the number of Aboriginal students enrolled in vocational education has increased substantially in many Australian states and territories, including the Australian Capital Territory, the Northern Territory, New South Wales and Western Australia, and especially in rural and remote regions (The Canberra Times 2012; Standing Council on School Education and Early Childhood 2013; The Centralian Advocate 2013). For example, in New South Wales, there were 5,160 Aboriginal students enrolled in VET courses in 2012 while in the Northern Territory 1,850 Aboriginal students received school-based VET training in the same year (Standing Council on School Education and Early Childhood 2013). In all Australia, the number of Aboriginal VET enrolments in 2012 was 12,632, a significant increase from 8,871 in 2002 (Standing Council on School Education and Early Childhood 2013). This upward trend is in line with the Aboriginal and Torres Strait islander education action plan 20101014, which aims at, among other targets, 'providing opportunities for Aboriginal and Torres 
Strait Islander students to participate in VET in Schools courses' (Standing Council on School Education and Early Childhood 2013, 89).

The case study VET school where the research took place was attended by nearly 70 Aboriginal students aged 14-20 coming from remote areas. Most of the students spoke an Aboriginal language at home while a few were Kriol or Aboriginal English speakers. The school had 19 staff members, including VET teachers, principal, deputy principal and support staff, the majority of whom were Anglo-Australian except for three, who were Aboriginal.

To obtain staff members' views on the issue of code-switching and how they assisted Aboriginal students' linguistic transition into the workplace, semi-structured informal interviews were conducted over a prolonged period. In addition, qualitative data from nonparticipant observations were also collected over a period of 18 months both in classroom and during visits to workplace training sites. Hand-written field notes were taken along with recorded data. To triangulate this school and workplace data, five female, seven male students, 57 Aboriginal community members, and ten non-Aboriginal work placement employers were also interviewed. Data were then coded to identify emergent themes.

The triangulation of the multiple data sources showed that Aboriginal students demonstrated oral communication patterns which disadvantaged them in the workplace, for example, an unwillingness to use verbal greeting and leave-taking, and an avoidance of eye contact with interactants. For example, one Aboriginal student was observed to respond to his placement supervisor's greeting with downcast eyes and a nod of the head. Moreover, although student interviewees indicated that the development of their oral skills played a salient role in the facilitation of their vocational and social integration into the work place, they demonstrated a reluctance to ask for task clarification for fear of getting shame, an Aboriginal concept referring to a fear of disgrace or loss of face when exhibiting a potential weakness (Oliver, Grote, Rochecouste and Exell 2013a, 2013b, 2012). The Aboriginal students in this cohort were also observed to experience remarkable difficulty in communicating with nonAboriginal people about work. This was due to a deficiency in work-related vocabulary, heavy Kriol pronunciation and, most importantly, an absence of code-switching skills between SAE and their first language/dialect.

Not only struggling to communicate about work, Aboriginal students were also reported by employers to lack conversational skills to engage in small talk with their non-Aboriginal colleagues in work placement. This finding is consistent with Mushin and Gardner's (2009) study, which reported that their Aboriginal participants usually exhibited long periods of silence in communicative exchanges. Nevertheless, it is worth noting that "silences are not interpreted by Aboriginal interlocutors as indicating that communication has broken down" (Eades 2000, 167), as this is their conversational style, especially of those who live in remote communities. Contrary to the Western communicative style, silence is highly valued by Aboriginal people for it gives them time to think or simply signals their enjoyment of the other person's presence (Eades 2013). However, their silence in interacting with AngloAustralians is often negatively interpreted as a sign of unfriendliness or lack of co-operation (Eades 2013). In our case study, the students' reticence and avoidance behaviour was found 
to create considerable discomfort in the workplace, especially in small businesses where employees work side by side on a daily basis. The Aboriginal students' quietness and shyness also frequently contributed to communication breakdown and misunderstanding in the workplace.

The VET instructors, while not language and literacy experts, but with trade expertise, were in a good position to help their students to transition into the workplace. Interview data showed that most VET instructors agreed that the students' ability and willingness to verbalise whether they understood instructions or not and to seek clarification was crucial to workplace success, therefore, indicating the need for Aboriginal students to develop the communicative ability in SAE to do these things. Instructors acknowledged that their students needed to develop the ability to successfully code-switch, as they needed SAE to operate successfully in the workplace, but also their first language or dialect to maintain positive selfidentity and strong ties with their communities. However, the data showed that teaching staff, including Aboriginal staff members, generally held the view either that code-switching would be detrimental to learning a new dialect or language. They simply had little awareness of the benefits of code-switching in building their students' confidence in communicating and socialising with non-Aboriginal co-workers, employers, and clients. While school staff often operated from this perspective, Aboriginal community members appeared to be more progressive in their opinions pointing out that the practice of code-switching in the safe confines of the classroom would equip students in preparing for the workplace. Community members indicated that the youth from their communities 'need to learn when to codeswitch... they already do it, but still need to talk about it' and that teachers 'need to start teaching code-switching skills to younger students'.

\section{Teacher attitudes to code-switching}

The response we found from teaching staff in our case study aligns with previous research on teachers' negative attitudes towards code-switching and the use of Aboriginal students' first language/dialect in the classroom. Teachers' attitudes such as 'If Aboriginal students are allowed to code-switch (move from one dialect or language to another) when they are beginning to learn Standard Australian English, it will be difficult for them to speak Standard Australian English correctly later on' (Oliver et al. 2011, 70) are, sadly, still common among a large number of teachers. In a study that examined 104 Western Australian teachers' awareness of Aboriginal English, Oliver et al. (2011) reported that a substantial number of teachers from metropolitan schools regarded dialectal forms of Aboriginal English as 'incorrect' and/or 'inappropriate' (Oliver et al. 2011, 71). Earlier, Haig and Oliver (2003b) examined the perceptions of 36 teachers from 12 schools in Western Australia and found that the teachers had a tendency to label Aboriginal students' speech as 'non-standard', 'restricted' and/or 'inappropriate', indicating their lack of acknowledgement of students' existing linguistic skills. Likewise, teachers from two primary and two secondary Western Australian schools in Haig and Oliver's (2003a) study criticised Aboriginal students' language as 'short', 'simple', and 'incomplete'. Consistent with these findings, Oliver and 
Haig (2005) reported that most of the 172 teachers from primary, district high and secondary Western Australian schools in a survey expressed conservative attitudes towards Aboriginal students' use of their home languages/dialects that deviated from standard English. These studies illustrate teachers' lack of support for the incorporation of Aboriginal students' home language in classroom communication.

In contexts outside Australia, Martin (1999) reported that Brunei teachers from two primary schools expressed reservations about deviation from monolingual education. In Botswana, Mokgwathi and Webb's (2013) participants from four senior secondary government schools also expressed concern that code-switching may stifle class participation in English, make students less confident in speaking English and affect their written communication skills. In the United States, Ramirez and Milk (1986) found that code-switching was perceived as an unacceptable behaviour by the teachers, who indicated that they were more willing to tolerate ungrammatical English than students' code-switching. Also in the United States, Siegel (2006) quotes teachers' concerns regarding the use of the home vernacular in the classroom. These teachers maintained that code-switching to the home vernacular wastes valuable class time that could be spent on learning standard English; that it causes interference in standard English acquisition; and that it could put Aboriginal students at a disadvantage by not providing them with educational equity.

Added to this, research has revealed teachers' own admissions that they do not have sufficient training and knowledge to teach Aboriginal students from non-English-speaking backgrounds. For instance, $40 \%$ of the surveyed teachers in Oliver et al.'s (2011) study indicated that, while they understood what Aboriginal English is, they were not confident with their linguistic understanding of this variety.

Yet it is clear that teachers' awareness of and attitudes towards code-switching need to be changed to understand that code-switching, rather than disadvantaging Aboriginal students, is actually a language resource that can facilitate educational development (e.g. Siegel 2006; Setati, Adler, Reed and Bapoo 2002; Then and Ting 2011). As described earlier, it has multiple benefits with respect to cognitive development, enhancement of academic attainment, and the validation of Aboriginal identity. Moreover, Aboriginal students' home language or dialect should be regarded as a valuable asset, not a hindrance to the learning process. It is important that this understanding be developed in pre-service teachers. In line with this suggestion, the Ministerial Council on Education, Employment, Training and Youth Affairs (MCEETYA) has clearly stated in the Aboriginal and Torres Strait Islander Education Action Plan (2010-2014, 25): 'Education providers will deliver professional learning to teachers to ensure high levels of cultural and linguistic understanding and competencies to inform the best teaching strategies for Aboriginal and Torres Strait Islander students.' 


\section{Education policies supporting code-switching}

To achieve these aims, it is necessary, as outlined above, for Aboriginal English/language to be accepted in the classroom and further, for this to be embedded in school policies to provide clear guidelines on code-switching instruction and to create systematic curriculum resources for teachers to use. Only when teachers are supported in this way will Aboriginal students' code-switching needs be addressed.

In recent years, efforts have been made in certain Australian states to promote the use of code-switching in the classroom. In New South Wales, for example, teaching staff in Focus schools are required to attend training workshops in English as an Additional Language or Dialect (EAL/D) pedagogies to provide effective support to Aboriginal students in bidialectal curriculum (Standing Council on School Education and Early Childhood 2013). In Western Australia, several publications have been produced to raise teachers' awareness of Aboriginal students' code-switching and their appreciation of the value of this pedagogical resource in the maintenance of Aboriginal identity by the Department of Education and Training (2005) and Department of Education, and Department of Training and Workforce Development $(2012)^{2}$. These resources stress that 'Teachers and school communities should understand how to broaden their students' linguistic repertoires to the extent that they are able to code-switch at will between language varieties' (Department of Education and Training, 2005 67). In the teaching resource entitled 'Tracks to Two-Way Learning' (Department of Education and Department of Training and Workforce Development WA 2012), tasks have been developed to enhance educators' pedagogical skills for promoting their Aboriginal students' consciousness of, and confidence in, their existing code-switching abilities. Added to this, the resource includes analytical activities organised to explicitly contrast between the two codes/dialects and assist speakers of Aboriginal English to recognise how their variety differs from SAE. These activities are based on the premise that a 'lack of awareness can lead to low self-esteem and inability to succeed' (Department of Education and Department of Training and Workforce Development WA 2012, Focus Area 12, 165). Discussion activities are also embedded in the resource to foster educators' understanding between learning English as a first language and learning English as an additional language or dialect.

However, it should be noted that pedagogical activities that focus on only formal dialectal differences (e.g. grammar and phonology) at the expense of contextual oral usage will not bring positive results, as students need to learn to make adjustments which accord with a range of communicative events to be successful at code-switching (Peltier 2010). Therefore, classroom tasks need to be developed that allow Aboriginal students to learn about and to practice code-switching for authentic purposes. For example, teachers could set up roleplaying scenarios to demonstrate how to use each code in appropriate contexts (e.g. audience, purpose, and setting), such as serving customers, conversing formally and informally, and also negotiating communication difficulties rather than remaining silent. By acknowledging and encouraging Aboriginal students' home language and their ability to code-switch,

\footnotetext{
${ }^{2}$ One of the authors of this paper, Dr. Rochecouste, was on the Academic Research and Resource Development team of this training resource.
} 
educators will enhance their students' sense of self-esteem, and thereby make learning a worthwhile and relevant experience.

\section{Assessment of code-switching to embrace plurality}

A change in pedagogical methods is by no means sufficient unless it is accompanied by a shift in assessment practices, since assessment has the 'patronising' (Preece and Skinner 1999, 15) power to regulate teaching and learning (Preece and Skinner 1999; Ketabi and Ketabi 2014). The current standardised norm-referenced assessment serves as a grave injustice to Aboriginal students. For instance, a number of assessment items used in tests such as NAPLAN have reportedly failed to account for Aboriginal communication styles and cultural backgrounds (Wigglesworth et al. 2011; Peltier 2010). As the assessment items are based on the SAE users (Wigglesworth et al. 2011), Aboriginal students in general, and Aboriginal students living in remote regions in particular, are disadvantaged. For instance, Aboriginal students in remote areas who have never had newspapers delivered to their home may find it hard to digest a reading passage on newspaper delivery complaints, as was the case in the Year 3, 2008 NAPLAN reading test (Wigglesworth et al. 2011). Likewise, Aboriginal students growing up in remote communities who have never been to a cinema may have difficulty comprehending the concept of a film poster as evident in the same NAPLAN reading test (Wigglesworth et al. 2011). Aboriginal students' lack of familiarity with cultural knowledge coupled with the absence of linguistic plurality in assessment results in low academic achievement, which may in turn lead to a misinterpretation of their speech, language and learning abilities.

To make assessment more relevant and to enable formal education to be situated within Aboriginal students' culture (Wishart 2009), one of the effective measures is the development of summative and formative tasks to evaluate Aboriginal code-switching skills. Rather than an exclusive concentration on the assessment of reading and writing skills, we argue that an assessment tool for oral skills, which takes into account Aboriginal students' prior oral linguistic knowledge and code-switching ability, should be developed. As J. Gardner (2012, 2, emphasis original) rightly points out, what we need is "assessment for learning" while at present educational focus is mostly on "assessment of learning". To that end, formative assessment that is cognizant of Aboriginal students' home languages and communication patterns should be given more weight than a final summative assessment of learning, which "potentially [does] not contribute to the students' learning" (J. Gardner 2012, 2).

\section{Conclusion}

Aboriginal parents want their children to be proud of their Aboriginality (Department of Education and Training 2005, 67) and at the same time, they would like their children to learn the 'Gudia (white fella) way so they can move between both worlds smoothly' (Public Health Advocacy Institute WA 2013, 30). This smooth transition can only occur by maintaining the 
home language/dialect within the new educational context. The acknowledgement and development of code-switching skills is fundamental in this process. Instead of branding Aboriginal students' English as 'bad', 'inappropriate', 'incorrect' or 'broken' (McRae et al. 2002, 17; Oliver et al. 2011, 71; George and George 2010, 2), teachers need to acknowledge dialectal differences and provide explicit modelling as to when, where, and with whom to use which speech repertoire. At the same time, it is important that teachers honour and value Aboriginal English as a representation of their culture and identity. Only in this way can Aboriginal students 'build self-esteem, take risks and engage in learning at school' (New South Wales Department of Education and Training 2008, para. 7). Added to this, policy makers need to re-evaluate current literacy assessment designs and develop a form of assessment that is more culturally familiar and relevant to Aboriginal students 'to address [their] social and spiritual realities' (McKeough et al. 2013, 149). Only by embracing plurality in curriculum and assessment will Aboriginal students' prior linguistic knowledge be recognised and their communicative competence in both their home language/dialect and SAE be effectively developed.

\section{References}

Atleo, M. R., and L. Fitznor. 2010. Aboriginal educators discuss recognizing, reclaiming, and revitalizing their multi-competences in heritage/English-language use. Canadian Journal of Native Education, suppl. Aboriginal Englishes and Education 32, supplement: 13-34,154.

Australian Government. 2013. Closing the gap on Indigenous disadvantage. http://www.indigenous.gov.au/closing-the-gap-on-indigenous-disadvantage/ (accessed 4 May, 2014).

Ball, J. 2009. Aboriginal young children's language development: Promising practices and needs. Canadian Issues Winter 2009: 37-44.

Bessarab, D., and B. Ng'andu. 2010. Yarning about yarning as a legitimate method in Indigenous research. International Journal of Critical Indigenous Studies 3, no. 1: 3750.

Blackburn, A. M. 2013. A study of the relationship between code-switching and the bilingual advantage: Evidence that language use modulates neural indices of language processing and cognitive control. Doctor of Philosophy, The University of Texas at San Antonio, Ann Arbor. 3607533.

http://search.proquest.com.dbgw.lis.curtin.edu.au/docview/1493850293/D105FFF08F1 $\underline{0478 \mathrm{EPQ} / 1 \text { ?accountid=10382 }}$ (accessed 7 May, 2014).

Byrd, D. 2012. Cognitive benefits of being bilingual. Journal of the Washington Academy of Sciences 98, no. 3: 19-30. 
Chilcott, T. 2012a. NAPLAN uncovers struggling students. The Courier-Mail 18 Sep 2012: 5.

Chilcott, T. 2012b. System fails indigenous pupils. The Courier-Mail 19 Sep 2012: 9.

Chilcott, T. 2013. NAPLAN report's shock on spelling. The Courier-Mail 14 Dec 2013: 7.

Cobern, W. 1996. Worldview theory and conceptual change in science education. Science Education 80, no. 5: 579-610.

Department of Education and Department of Training and Workforce Development WA 2012. Tracks to Two-Way Learning, Focus Area 1. Western Australia: WestOne Services.

Department of Education and Department of Training and Workforce Development WA. 2012. Tracks to Two-Way Learning, Focus Area 12. Western Australia: WestOne Services.

Department of Education and Training. 2005. Walk right in: You can make a difference. East Perth, WA: Department of Education and Training.

Eades, D. 2000. I don't think it's an answer to the question: Silencing Aboriginal witnesses in court. Language in Society 29, no. 2: 161-195.

Eades, D. 2013. Aboriginal ways of using English. Canberra: Aboriginal Studies Press.

Feldman, C., A. Stone, and B. Renderer. 1990. Stage, transfer, and academic achievement in dialect-speaking Hawaiian adolescents. Child Development 61, no. 2: 472-484.

Forrest, S. 2013. Boodja Marr Karl: A whole-community approach to Aboriginal education The development of a cultural framework for Aboriginal participation in education and schooling. In Vulnerable Children: Global Challenges in Education, ed. D.J. Johnson D.L. Agbényiga, and R.K. Hitchcock, 71-81. New York: Springer.

Gardner, J. 2012. Assessment and learning. London: SAGE.

Gardner, R., \& Mushin, I. 2013. Language for learning in Indigenous classrooms: Foundations for literacy and numeracy. In Pedagogies to Enhance Learning for Indigenous Students: Evidence-based Practice, ed. R. Jorgensen, P. Sullivan, and P. Grootenboer, 89-104. Singapore: Springer. DOI 10.1007/978-981-4021-84-5_6

George, N., and E. P. George. 2010. Foreword: Honoring who we are. Canadian Journal of Native Education 32, supplement: 1-3.

Griffiths, E. 2014. Closing the Gap: Tony Abbott delivers mixed report card on Indigenous disadvantage. Sydney: Australian Broadcasting Corporation. http://search.proquest.com.dbgw.lis.curtin.edu.au/docview/1497210136?accountid=103 $\underline{82}$ (accessed 4 May, 2014). 
Grosjean, F. 1999. Individual bilingualism. In Concise Encyclopedia of Educational Linguistics, ed. B. Spolsky, 284-290. London: Elsevier.

Haig, Y., and R. Oliver. 2003a. Is it a case of mind over matter? Influences on teachers' judgements of student speech. Australian Review of Applied Linguistics 26, no. 1: 5570 .

Haig, Y., and R. Oliver. 2003b. Language variation and education: Teachers' perceptions. Language education 17, no. 4: 266-280.

Hornberger, N. H., and K. F. Swinehart. 2012. Bilingual intercultural education and Andean hip hop: Transnational sites for indigenous language and identity. Language in Society 41, no. 4: 499-525.

Hughes, H., and M. Hughes. 2012. Indigenous education 2012. Centre for Independent Studies (Australia). https://www.cis.org.au/images/stories/policy-monographs/pm129.pdf (accessed 4 May, 2014).

The Centralian Advocate. 2013. "Indigenous education transforms lives and communities." 27 Aug 2013: 13.

Lavoie, C., M. Sarkar, M. P. Mark, and B. Jenniss. 2012. Multiliteracies pedagogy in language teaching: An example from an Innu community in Quebec. Canadian Journal of Native Education 35, no. 1: 194-210,222-224.

Ljungberg, J. K., P. Hansson, P. Andrés, M. Josefsson, and L. G. Nilsson. 2013. A Longitudinal study of memory advantages in bilinguals, PLoS One 8, no. 9: 1-8.

Ketabi, S., and S. Ketabi. 2014. Classroom and formative assessment in second/foreign language teaching and learning. Theory and Practice in Language Studies 4, no. 2: 435440.

Klapproth, D. M. 2004. Narrative as social practice: Anglo-Western and Australian Aboriginal oral traditions. Berlin: Walter de Gruyter.

Kieswetter, A. 1995. Code-switching amongst African high school pupils within different social contexts. MA dissertation, University of Witwatersrand, Johannesburg. http://wiredspace.wits.ac.za/handle/10539/10972 (accessed 8 August 2013).

Kirk, A. 2012. Garrett: NAPLAN results show states need to back Gonski plan. The World Today, Sydney: Australian Broadcasting Corporation. http://search.proquest.com.dbgw.lis.curtin.edu.au/docview/1239293096?accountid=103 $\underline{82}$ (accessed 4 May, 2014).

Lo Bianco, J. 2008. Bilingual education and socio-political issues. In Encyclopedia of language and education, Volume 5: Bilingual Education, ed. J. Cummins and N. H. Hornberger, 35-50. LLC: Springer Science + Business Media. 
Malcolm, I., and J. Rochecouste. 2000. Event and story schemas in Australian Aboriginal English discourse. English World-Wide 22, no. 2: 95-123.

Martin, P.W. 1999. Close encounters of a bilingual kind: Interactional practices in the primary classroom in Brunei. International Journal of Educational Development 19, no. 2: $127-140$.

MCEETYA. 2010-2014. Aboriginal and Torres Strait islander education action plan. http://www.mceecdya.edu.au/verve/_resources/a10-0945_ieap_web_version_final2.pdf (accessed 25 April 2014).

McKeough, A., S. Bird, E. Tourigny, A. Romaine, S. Graham, J. Ottmann, and J. Jeary. 2008. Storytelling as a foundation to literacy development for Aboriginal children: Culturally and developmentally appropriate practices. Canadian Psychology 49, no. 2: 148-154.

McRae, D., G. Ainsworth, P. Hughes, K. Price, M. Rowland, J. Warhurst, D. Woods, and V. Zbar. 2002. What works. The work program. Improving outcomes for Indigenous students. The guidebook. Canberra: Australian Curriculum Studies Association and National Curriculum Services.

McGregor, K. 2011. As public schools elevate student attendance as a priority. . . 5200 a day skip school. The Advertiser 10 May 2011: 5.

Mokgwathi, T., and V. Webb. 2013. The educational effects of code-switching in the classroom - benefits and setbacks: A case of selected senior secondary schools in Botswana. Language Matters 44, no. 3: 108-125.

Moschkovich, J. 2005. Using two languages when learning mathematics. Educational Studies in Mathematics 64: 121-144.

Mushin, I., and R. Gardner. 2009. Silence is talk: Conversational silence in Australian Aboriginal talk-in-interaction. Journal of Pragmatics 41, no. 10: 2033-2052.

New South Wales Department of Education and Training. 2008. Supporting Aboriginal Students. http://www.schools.nsw.edu.au/learning/712assessments/naplan/teachstrategies/yr2008/numeracy/aboriginal students/NN AbSt O.htm U (accessed 7 May, 2014).

Oliver, R., E. Grote, J. Rochecouste, and M. Exell. 2013a. A task-based needs analysis for Australian Aboriginal students: Going beyond the target situation to address cultural issues. International Journal of Training Research 11, no. 3: 246-259.

Oliver, R., E. Grote, J. Rochecouste, and M. Exell. 2013b. Needs analysis for task-based language teaching: A case study of Indigenous vocational education and training students who speak EAL/EAD. TESOL in Context 22, no. 2: 36-50. 
Oliver, R., E. Grote, J. Rochecouste, and M. Exell. 2012. Addressing the Language and Literacy Needs of Aboriginal High School VET Students who Speak SAE as an Additional Language. Australian Journal of Indigenous Education 41, no. 2: 1-11.

Oliver, R., and Y. Haig. 2005. Teacher perceptions of student speech: A quantitative study. Australian Review of Applied Linguistics 28, no. 2: 44-59.

Oliver, R., J. Rochecouste, S. Vanderford, and E. Grote. 2011. Teacher awareness and understandings about Aboriginal English in Western Australia. Australian Review of Applied Linguistics 34, no. 1: 60-74.

Peltier, S. 2008. Preface. Clinical Linguistics and Phonetics 22, no. 8: 567-569.

Peltier, S. 2010. Facilitating language and literacy learning for students with Aboriginal English dialects. Canadian Journal of Native Education, suppl. Aboriginal Englishes and Education 32, supplement: 114-142,155.

Peterson, S. S. 2012. Action research supporting students' oral language in Northern Canadian schools: A professional development initiative. Journal of Research in Rural Education 27, no. 10: 1-16.

Pi-Sunyer, O. 2007. Indigenous peoples' wisdom and power: affirming our knowledge through narratives. Choice 45, no. 1: 140.

Pond, M. 2012. School at a loss to stop 'wagging' students. Central Midlands and Coastal Advocate.

http://search.proquest.com.dbgw.lis.curtin.edu.au/docview/931057215?accountid=1038 $\underline{2}$ (accessed 7 May, 2014).

Preece, P. F. W., and N. C. Skinner. 1999. The national assessment in science at Key Stage 3 in England and Wales and its impact on teaching and learning. Assessment in Education 6, no. 1: 11-27.

Public Health Advocacy Institute WA. 2013. The West Australian Indigenous Storybook. Fremantle WA: Makomedia.

Ramirez, A. G., and R. D. Milk. 1986. Notions of grammaticality among teachers of bilingual pupils. TESOL Quarterly 20, no. 3: 495-513.

Richardson, J. 2013. Aboriginal student keen to inspire others. The Examiner, 08 Sep 2013, p.49.

Santow, S. 2010. Report points to failures in Aboriginal education. Sydney: Australian Broadcasting Corporation.

Schwab, G. R. 2001. VET-in-school for Indigenous students: Success through "cultural fit". http://booroongendjugun.com.au/wp-content/uploads/2012/03/VET-in-School-forIndigenous-Students.pdf (accessed 7 May, 2014). 
Selby, S. 2013. First person plural: Aboriginal storytelling and the ethics of collaborative authorship. British Journal of Canadian Studies 26, no. 2: 294-295.

Setati, M., and J. Alder. 2001. Between languages and discourses: Language practices in primary multilingual mathematics classrooms in South Africa. Educational Studies in Mathematics 43: 243-269.

Setati, M., J. Adler, Y. Reed, and A. Bapoo, A. 2002. Incomplete journeys: Code-switching and other language practices in mathematics, science and English language classrooms in South Africa. Language and Education 16, no. 2: 128-149.

Sharifian, F. 2000. Aspects of schematic processing in Indigenous speakers of Aboriginal English: An initial exploration. http://cogprints.org/1249/ (accessed 18 March, 2014).

Sharifian, F. 2008. Aboriginal English in the classroom: An asset or a liability? Language Awareness 17, no. 2: 131-138.

Shizha, E. 2007. Critical analysis of problems encountered in incorporating Indigenous knowledge in science teaching by primary school teachers in Zimbabwe. Alberta Journal of Educational Research 53, no. 3: 302-319.

Siegel, J. 2006. Keeping Creoles and dialects out of the classroom. In Dialects, Englishes, creoles, and education, ed. S. Nero, 39-70. Mahwah, New Jersey: Lawrence Earlbaum Associates.

Smail, S. 2012. Calls to overhaul Indigenous education after poor NAPLAN results. The World Today, Sydney: Australian Broadcasting Corporation. http://search.proquest.com.dbgw.lis.curtin.edu.au/docview/1239896767?accountid=103 $\underline{82}$ (accessed 4 April, 2014).

Standing Council on School Education and Early Childhood. 2013. Aboriginal and Torres Strait Islander Education Action Plan 2010-2014: 2012 Annual Report. Carlton, South Victoria. http://www.scseec.edu.au (accessed 4 May, 2014).

Stevenson, A. 2012. Aboriginal funds need redirecting- report. Sydney Morning Herald 27 June 2012: 6 .

The Canberra Times. 2012. "ACT vocational education on the rise.” 06 July 2012: 6.

Then, D. C. and S. Ting. 2011. Code-switching in English and science classrooms: more than translation. International Journal of Multilingualism 8, no. 4: 299-323.

Tian, L., and E. Macaro. 2012. Comparing the effect of teacher code-switching with Englishonly explanations on the vocabulary acquisition of Chinese university students: A Lexical Focus-on-Form study. Language Teaching Research 16, no. 3: 367-391. 
Uys, D., and O. Van Dulm. 2011. The functions of classroom code-switching in the Siyanda District of the Northern Cape. Southern African Linguistics and Applied Language Studies 29, no. 1: 67-76.

Warren, E., and E. deVries. 2009. Young Australian Indigenous students' engagement with numeracy: Actions that assist to bridge the gap. Australian Journal of Education 53, no. 2: $159-175$.

Welch, A., P. Konigsberg, J. Rochecouste, and G. Collard. In Press. Aboriginal Education in Australia: Policies, Problems, Prospects. In Education in Australia, New Zealand and the Pacific, ed. Crossley, G. Hancock, and T. Sprague, T, Chap. 5. London: Bloomsbury.

Wigglesworth, G., J. Simpson, and D. Loakes. 2011. NAPLAN language assessments for Indigenous children in remote communities: Issues and problems. Australian Review of Applied Linguistics 34, no. 3: 320-343.

Wishart, D. 2009. Dynamics of education policy and practice for urban Aboriginal early school leavers. Alberta Journal of Educational Research 55, no. 4: 468-481.

Woods, A. 2010. Indigenous identity, oral tradition, and the land in the poetry of Oodgeroo Noonuccal, Luci Tapahonso, and Haunani-Kay Trask. Masters of English, East Carolina University, Ann Arbor. 1491114. http://hdl.handle.net/10342/3536 (accessed 7 May, 2014).

Zevenbergen, R., P. Grootenboer, and P. Sullivan. 2010. Good learning = A good life: Mathematics transformation in remote Indigenous communities. Australian Journal of Social Issues 45, no. 1: 131-143.

Zoellner, D. 2012. Dualism and vocational education and training: Creating the people who require training. International Journal of Training Research 10, no. 2: 79-93. 